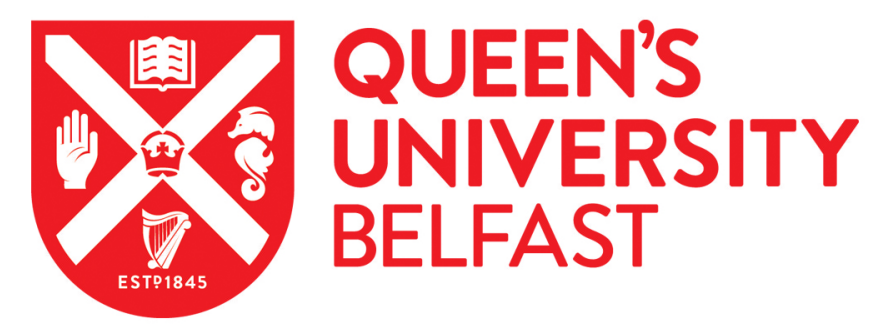

\title{
Smart Asset Management using Online Monitoring
}

Courtney, D., Littler, T., \& Livie, J. (2017). Smart Asset Management using Online Monitoring. In Proceedings of Centre International de Recherche sur l'Environnement et le Développement (CIRED) 2017 Conference (pp. 436-440). [263] IET. https://doi.org/10.1049/oap-cired.2017.0263

\section{Published in:}

Proceedings of Centre International de Recherche sur l'Environnement et le Développement (CIRED) 2017 Conference

\section{Document Version:}

Publisher's PDF, also known as Version of record

\section{Queen's University Belfast - Research Portal:}

Link to publication record in Queen's University Belfast Research Portal

\section{Publisher rights}

Copyright 2017 the authors.

This is an open access article published under a Creative Commons Attribution License (https://creativecommons.org/licenses/by/4.0/), which permits unrestricted use, distribution and reproduction in any medium, provided the author and source are cited.

\section{General rights}

Copyright for the publications made accessible via the Queen's University Belfast Research Portal is retained by the author(s) and / or other copyright owners and it is a condition of accessing these publications that users recognise and abide by the legal requirements associated with these rights.

Take down policy

The Research Portal is Queen's institutional repository that provides access to Queen's research output. Every effort has been made to ensure that content in the Research Portal does not infringe any person's rights, or applicable UK laws. If you discover content in the Research Portal that you believe breaches copyright or violates any law, please contact openaccess@qub.ac.uk. 


\title{
Smart asset management using online monitoring
}

\author{
David Courtney ${ }^{1}$, Jim Livie ${ }^{2}$, Tim Littler $^{3}$ \\ ${ }^{1}$ Embedded Monitoring Systems, Lisburn, UK \\ ${ }^{2}$ Scottish Power Energy Networks, Glasgow, UK \\ ${ }^{3}$ Queen's University, Belfast, UK \\ E-mail:dave@emsni.com
}

\begin{abstract}
Distribution network operators assess the condition and life expectancy of large capital assets, including circuit breakers (CBs) which are critical ageing assets. This study presents a scheme to monitor substations in South Scotland and North Wales and describes how online monitoring and analysis of protection operations is used to quickly identify immediate and evolving problems. This allows timely repairs and avoids possible CB failures with inherent mechanical damage or more widespread faults. The study includes several case studies using examples showing a range of asset fault types.
\end{abstract}

\section{Introduction}

Distribution network operators (DNOs) assess network components to extend asset life and minimise risk. Large capital assets like transformers and circuit breakers (CBs) require monitoring and reporting. DNOs must maintain an aging asset base and sustain capital expenditure to deliver a predictable return on investment. Network faults require immediate isolation by the protection system to minimise damage and limit impacts on quality of service (QoS). QoS incentives provide annual rewards and penalties which depend on DNO performance including a measure of customer minutes lost (CML).

Asset maintenance has moved from regular interval servicing to reliability centred method (RCM) and condition-based method (CBM). Simple CB operation counters use supervisory control and data acquisition (SCADA) data but more comprehensive systems require dedicated monitors during offline maintenance or permanently located in substations with online connection. The advantage of online systems is that all operations are monitored and issues reported immediately. Additionally, cleared fault currents per phase can be recorded and main contact duty calculated and used as part of a RCM/CBM scheme.

Online data can provide situational information for accurate decision making. In $\mathrm{CB}$ monitoring, direct access to online trip and close coil currents can reveal actual or evolving faults with the mechanism, Fig. 1 [1, 2]. If the tripping battery voltage is also monitored the battery and connection state can be determined and faults reported. Thus a single online instrument can monitor the protection system in a substation including relays, $\mathrm{CBs}$ and the tripping battery. Furthermore, monitoring ambient temperature can indicate if slow operation is due to low temperatures affecting mechanism lubricants.

Online monitoring allows CBs to be tested remotely as manual operations from the DNO control room (tele-control) are analysed and test measurements are emailed to staff after each test in the same way as fault events.

Scottish Power Energy Networks (SPEN) has trialled an online system under an innovation funding incentive (IFI) scheme [3] in the Northern and Southern regional areas. This paper describes how online data from embedded instruments is used for analytical assessment of the protection system to identify key parameters and to determine potential faults in the mechanism and calculate operational duty. The scheme is being rolled out to over 700 primary substations and uses email reports to deliver fault and trend information directly to operational staff and a central server for viewing, archiving and further analysis.

\section{CB monitoring}

Distribution CBs vary in design and specification however mechanical operation and methods of connection are similar. A CB can be separated into two parts: (i) the mechanism that has stored energy with a release mechanism; and (ii) the main contacts that interrupt the three-phase current.

To maximise speed of operation energy stored in a compressed spring is released by a tripping mechanism controlled by a solenoid, Fig. 2. For faster operation the solenoid is overdriven by many times its continuous current rating. To protect the coils from damage auxiliary contacts connected to the tripping mechanism disconnect the battery supply once it has operated, Fig. 3. The trip and close coil current profiles are used to determine the state of the $\mathrm{CB}$ mechanism and identify the faulty section if the operating limits are exceeded.

Both trip and close operations are important. A failure to trip has greater consequences but a failure to close would delay the reconnection of customers and increase CML.

\subsection{Monitor connections and configuration}

A protection operation is characterised by a number of parameters obtained from the system using embedded monitoring units. The connected signals are: tripping battery voltage and current, auxiliary contacts and line currents obtained from the protection current transformers (CTs), Fig. 4. The battery current is measured using a Hall effect probe and the auxiliary contacts also determine which CB has operated. The installation is non-invasive as the line and battery currents use interposing split-core CTs so no interruption of the protection or battery wiring is required.

In practice, some substations have two batteries of different voltages for separate groups of breakers. In these cases there are two Hall effect probes and two battery voltage input modules (1DC).

Further parameters can be derived from the measurements to determine cumulative statistics for $\mathrm{CB}$ operation, including number of operations, cleared current and thermal duty $\left(I^{2} t\right)$ which can then be used to determine service intervals for asset planning and maintenance and configuration of monitoring units. 


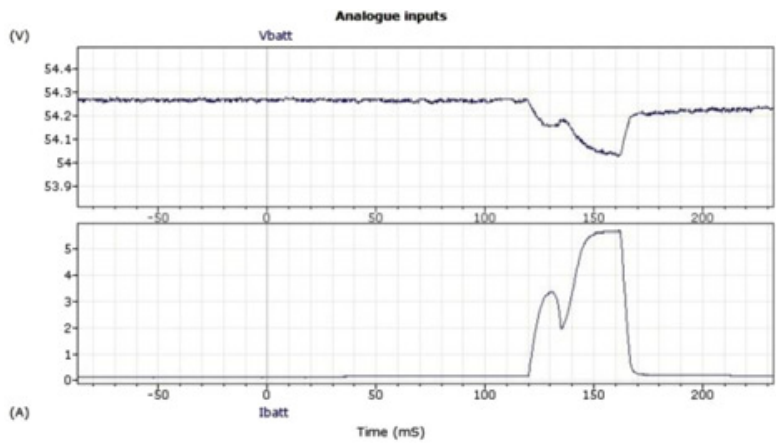

Fig. 1 Typical battery voltage (upper) and coil current (lower) profiles during a breaker trip

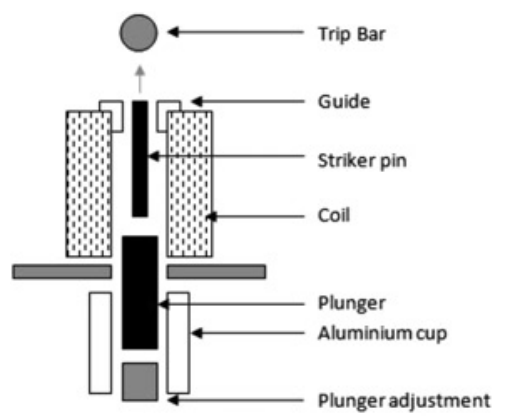

Fig. 2 Basic configuration of $C B$ trip and close coils

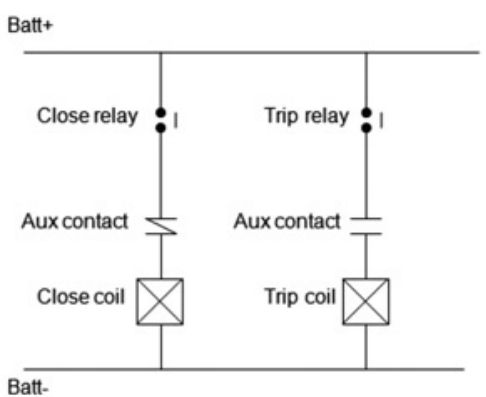

Fig. $3 C B$ trip and close coils driven by protection relay

The tripping battery voltage can be used as an indication of its condition but a more consistent scheme is to measure the battery source resistance during trip and close operations. If the value rises above a set limit then there may be an issue with the cabling, joints or a battery cell.

\subsection{CB measurement and fault diagnoses}

By monitoring breaker movements and measuring battery and contact operations, immediate faults in the protection system can be identified. Of particular importance to breaker diagnosis are the trip and close coil profiles, Fig. 5. The main contact operations are derived from the phase current signals.

There are other characteristics on certain profiles but they are not consistent across breaker types so are not used for analysis. Variations in parameters can reveal immediate or potential faults in operation. Moreover, sustained or increasing variation in one or more parameters may be indicative of evolving or longer term faults.

The shape of the coil profile can be used to help locate a fault. The plunger stop point (No. 3 in Fig. 5) separates solenoid and plunger

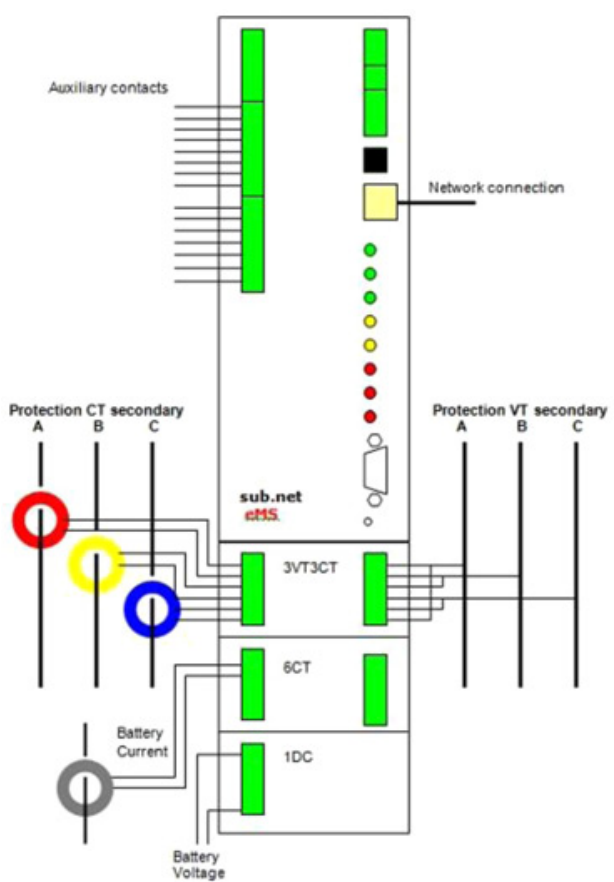

Fig. 4 Input connections to substation monitor

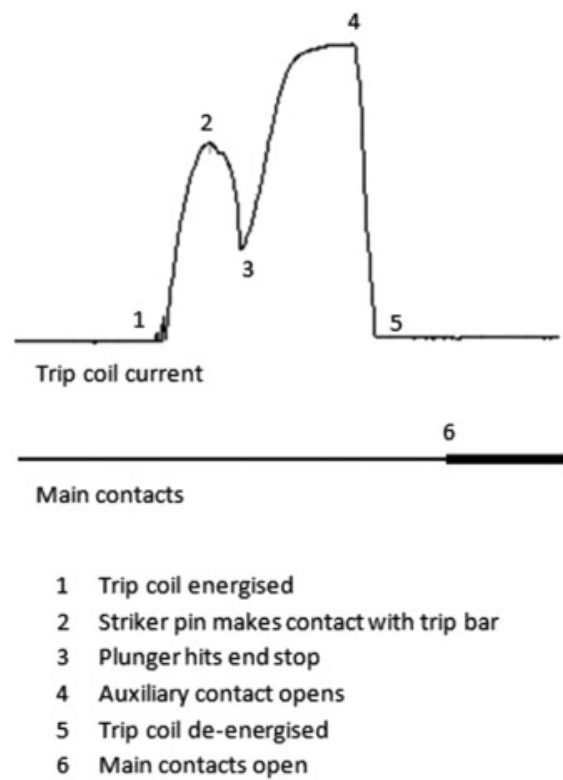

Fig. 5 Key points on a trip operation

issues from problems with the mechanism. Variations in the profile before Point 3 relate to the solenoid. For each breaker type, operating limits are configured using a web interface in the monitor. These include the operating time (main contacts), battery resistance and the maximum current and pulse width for the trip and close coils, Fig. 6. Ideally, all CBs at a substation have the same characteristics but during their lifetime faulty devices may be replaced by different types. For this reason operating limits in the monitor can support up to six different profiles.

There are detectable variations in the profiles of trip and close coils of the same breaker and between trip coils of the same breaker type. The system configuration can allow for these variations.

The event capture process that can include CB operations may be initiated in a number of ways including over and under levels of 


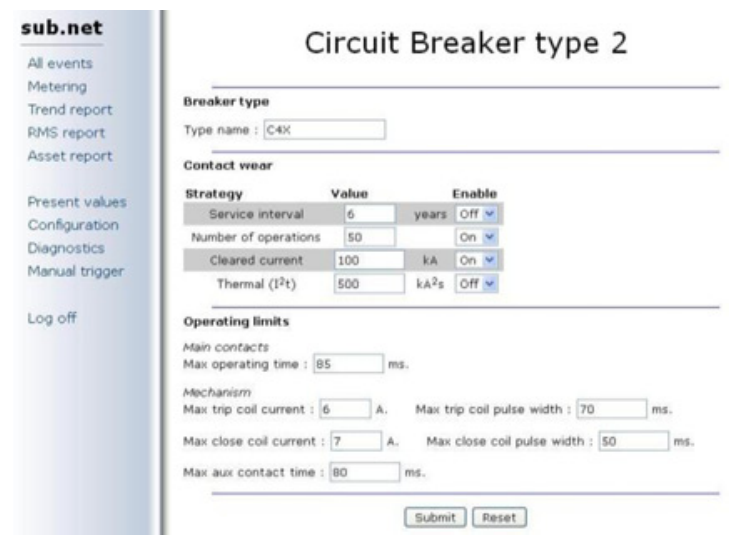

Fig. 6 Main contact wear and mechanism operating limits set in monitor

voltage and current and change of contact inputs. When complete an event is analysed and the measurements on the trip and close coil profiles, phase currents and contacts are made. The relevant values are then compared with the limit values and if exceeded the event report includes an 'asset fault' message and the event priority is increased.

The monitor allows for extended events that can occur during a recloser sequence where a source breaker can trip and close up to 7 times in quick succession. Each individual operation is analysed and measurements included in the event report.

The event report is emailed to registered users including the central server. The report contains a summary, graphs and tables including the measurements for each breaker operation. For the server the results are also attached in a standard web format (XML) which can be imported into other applications for further analysis. A summary of the key protection measurements included with the event report are the following sections.

\subsubsection{Phase current and contact measurements:}

- fault clearance time

- protection relay operate time

- maximum fault level

- cleared current per phase

- isolation of fault current per phase.

\subsubsection{Breaker and battery measurements:}

- breaker operate time

- trip/close pulse width and maximum current

- auxiliary contact operate time

- minimum battery voltage

- battery source resistance.

Although the asset reporting system operates directly, additional condition information can be yielded by trending the key parameters for each CB. Additionally, measurements from the same breaker types at different locations can be compared.

\section{CB monitoring scheme}

The SPEN substation monitoring scheme is being rolled out to over 700 primary substations using email reporting to deliver fault and trend information directly to staff and to a central iHost server [4] for viewing, archiving and further analysis.

The same monitor is used to deliver reports on fault location, power quality and load profiles. The monitor supports remote communication using Ethernet and wired or wireless telecom circuits. For this project the majority of systems currently use dial-up modems with the remainder on wireless or Ethernet. As the communication networks are upgraded the systems will be moved to Ethernet. As the measurements and analysis are undertaken in each monitor the system is scalable with no loss of performance.

\section{Asset fault type examples}

The traces and measured parameters in the following examples were obtained from email reports for real events sent directly from the monitor at each substation. All faults were referred to maintenance staff for later investigation, though an initial assessment of possible causes has been included in each case.

\subsection{Fault 1: CB failure to operate}

A $1 \mathrm{~s}$ trip pulse was received from the SCADA system, but there was no subsequent breaker movement, Fig. 7. The trip coil current was evident, but there was no actual trip release: the probable cause was solenoid or plunger jamming.

\subsection{Fault 2: $C B$ slow operation no. 1}

The CB exhibited a slow mechanism operation, though the trip release was valid, Fig. 8; probable cause was considered either a sluggish mechanism or partial charging of the trip spring.

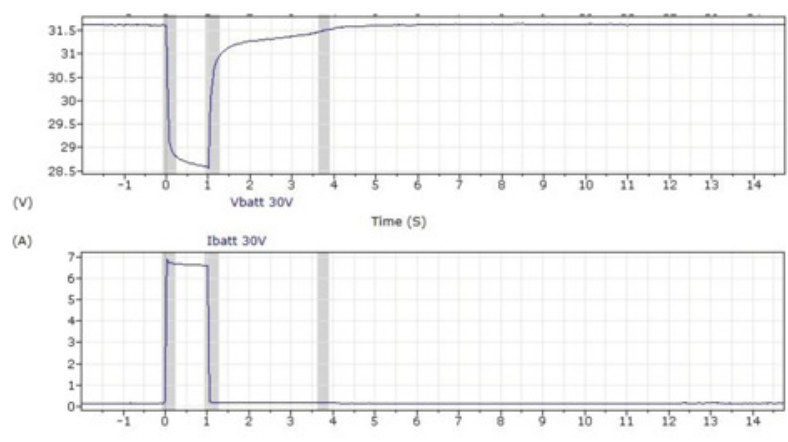

(Operation) at $1023.7 \mathrm{~ms}$

\begin{tabular}{|lc|}
\hline Coil current & $7.132 \mathrm{~A}$ \\
\hline Pulse width & $1025.4 \mathrm{~ms}$ \\
\hline Battery Vm & $28.144 \mathrm{~V}$ \\
\hline Battery impedance & $0.527 \mathrm{R}$
\end{tabular}

Fig. 7 No breaker operation despite SCADA trip

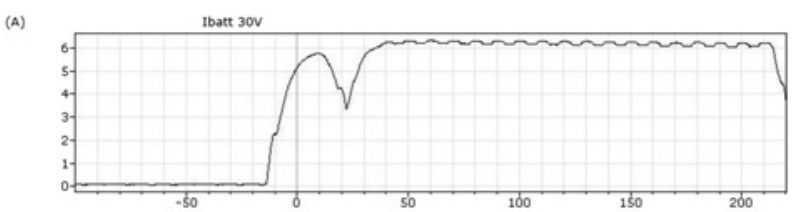

(Operation) at $224.5 \mathrm{~ms}$

\begin{tabular}{|lc|}
\hline Coil current & $6.207 \mathrm{~A}$ \\
\hline Pulse width & $238.2 \mathrm{~ms}$ \\
\hline Battery Vm & $31.861 \mathrm{~V}$ \\
\hline Battery impedance & $0.284 \mathrm{R}$
\end{tabular}

Fig. 8 Sluggish breaker mechanism 


\subsection{Fault 3: $C B$ slow operation no. 2}

As in the previous example, the trip release is valid, Fig. 9, but the mechanism stalled: the probable cause was a sluggish mechanism, however the minimum voltage and high source impedance indicate that the root cause may be with the battery.

\subsection{Fault 4: $C B$ slow operation no. 3}

In this case, Fig. 10, the trip release was slow: the probable cause appears to have been the plunger or striker pin in the trip mechanism.

\subsection{Fault 5: $C B$ failure to close}

This was a tele-controlled operation and the auxiliary contact (solid blue line) momentarily changes state, Fig. 11. This happened twice and the CB operated correctly on the third try. Probable cause is still under investigation but this example also shows how asset faults are shown in the event reports. A possible explanation is that the auxiliary contact isolating the close coil operated too early and the mechanism could not complete its action.

(A)
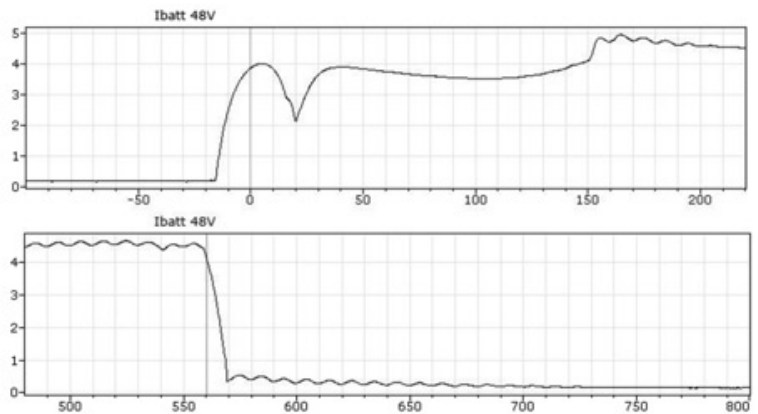

(Operation) at $\mathbf{5 6 9 . 1 ~} \mathrm{ms}$

\begin{tabular}{|cc|}
\hline Coil current & $4.751 \mathrm{~A}$ \\
\hline Pulse width & $548.7 \mathrm{~ms}$ \\
\hline Battery Vm & $40.925 \mathrm{~V}$ \\
\hline Battery impedance & $3.732 \mathrm{R}$
\end{tabular}

Fig. 9 Stalled breaker operation

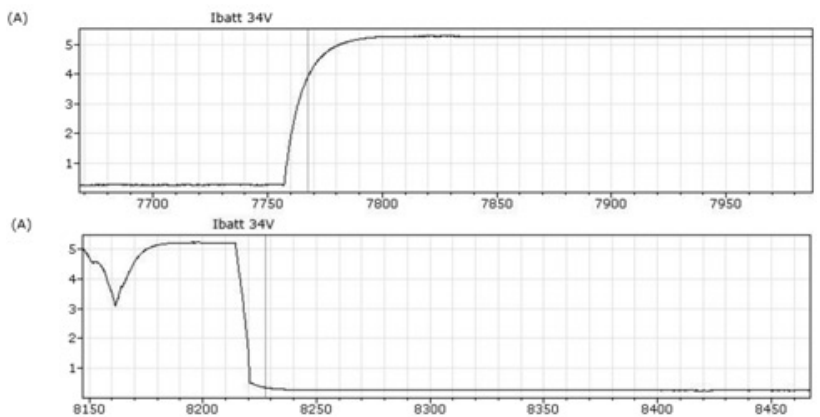

(Operation) at $\mathbf{8 2 2 2 . 5} \mathbf{~ m s}$

\begin{tabular}{|cc|}
\hline Coil current & $4.998 \mathrm{~A}$ \\
\hline Pulse width & $465.1 \mathrm{~ms}$ \\
\hline Battery Vm & $31.367 \mathrm{~V}$ \\
\hline Battery impedance & $0.227 \mathrm{R}$
\end{tabular}

Fig. 10 Problem with the trip plunger or striker pin
Asset Fault: CB487-4, Coil current 7.735 A

\begin{tabular}{lr}
\hline System & 487 \\
Class & Contact change \\
\hline Trigger & Analogue over, 10:Ibatt48 \\
Event priority & 1 \\
\hline Ambient temperature & $13.5 \mathrm{C}$
\end{tabular}

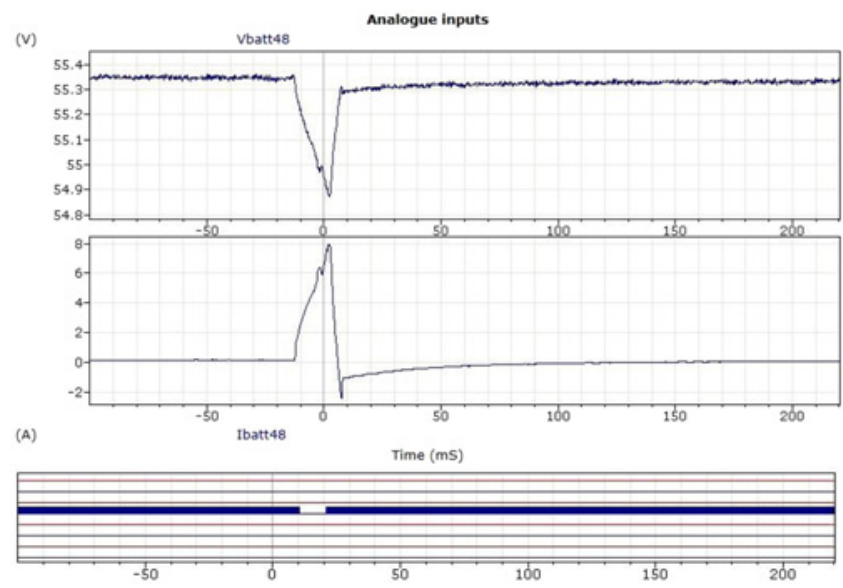

CB487-4 (Close) CCT1 at $6.1 \mathrm{mS}$

\begin{tabular}{lc} 
Coil current & $7.735 \mathrm{~A}$ \\
\hline Pulse width & $18.4 \mathrm{~ms}$ \\
\hline Aux contact & $22.50 \mathrm{~ms}$ \\
Battery Vm & $54.875 \mathrm{~V}$ \\
Battery impedance & $0.059 \mathrm{R}$
\end{tabular}

Fig. 11 Breaker failed to complete close operation

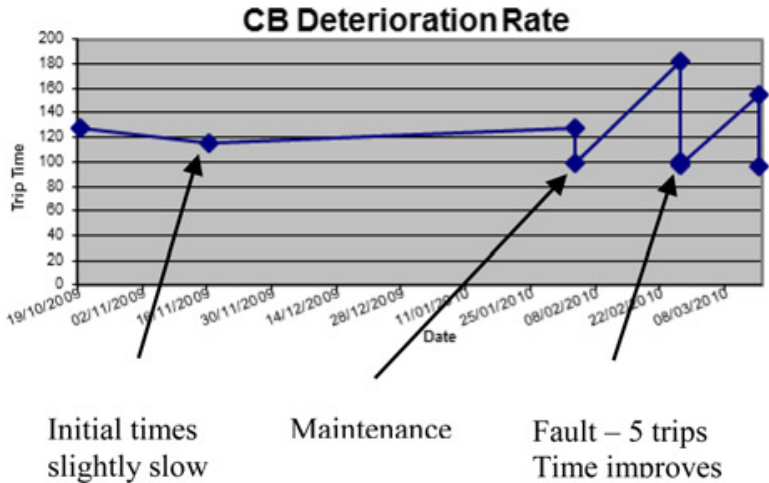

Fig. $12 C B$ deterioration over time

4.5.1 CB time trending: Key measurements extracted from event reports can be trended to look for evolving faults, Fig. 12. This annotated graph shows the operate times for a single breaker over 6 months. It can be seen that both a maintenance service and multiple operations improve the operate time. It is known that if a $\mathrm{CB}$ has not operated for many months its next operation can be slower due to a 'sticky' mechanism. Subsequent operations will return to normal speed as the mechanism has eased.

\section{Conclusion}

This paper has considered a scheme which has facilitated the development of an asset management policy for CBs by using 
online measurement of $\mathrm{CB}$ operations. Although trip coil profiling has been used for many years as a reliable method for determining the condition of $\mathrm{CB}$ mechanisms, online monitors that capture and analyse every operation give the best and most up to date information with the ability to immediately report non-standard operations and trend key measurements. This delivers measurable benefits to minimise breaker failures and hence reduce consequential losses from mechanical damage and increased CML penalties. The scheme provides a smart method for remote diagnostics by using online monitoring of substation measurements to render rapid access to $\mathrm{CB}$ operation by simple email reporting for example to smart phone or tablet computers. The online substation measurements supply immediate information to identify a fault or potential faults while collating useful statistical information over time to trend breaker operations and duty.

\section{References}

1 Henderson, R., Seeds, D.: 'Condition assessment of circuit breakers using a trip coil profiling approach'. IEE Colloquium on Monitors and condition assessment equipment, Digest No: 1996/186, 8/1-8/13, 1996

2 Courtney, D., Gillespie, D.: 'Practical experience of using on-line circuit breaker testing to implement a condition based maintenance strategy'. Proc. DistribuTECH Conf., San Diego, USA, 2004

3 SP Energy Networks: 'IFI-0709 Sub.net monitoring'. IFI Annual Report 2008-09, SP Energy Networks, Glasgow, vol. 12 (2009), pp. 69-70

4 Nortech Management Ltd: 'iHost Platform, 2017'. Available: http://www. ihostexplained.co.uk accessed: 12 January 2017 